Journal of Economics and Behavioral Studies

Vol. 6, No. 4, pp. 302-309, Apr 2014 (ISSN: 2220-6140)

\title{
The Organizational Innovativeness Inventory for information and electronic enterprises: Development and Validation
}

\author{
Li-Min Chuang ${ }^{1}$, Chun-Chu Liu ${ }^{2}$, Wen-Chia Tsai1,2 \\ ${ }^{1}$ Chang Jung Christian University, Taiwan \\ ${ }^{2}$ WuFeng University, Taiwan \\ *wenchtsai@gmail.com
}

\begin{abstract}
The primary purpose of this study is to develop Taiwan localization and suitable inventory for the measuring organizational innovation in information and electronic enterprises. In review of relevant literatures, and with reference to opinions from scholars and practical experience from enterprises, the framework of the inventory would be initially established. Concerning the inventory reliability, Cronbach's $\alpha$ coefficient, item-total correlation and test-retest reliability coefficient have been employed to test the extent of internal consistency and the stability of the inventory. In the construction of validity, Linear Structural Relation was adopted to carry out confirmatory factor analysis. The suitability and fitness of the seven dimensions and 58 questions have been thus verified. As a result, this inventory with adequate validity and reliability can serve as effective instrument for the measurement of organizational innovation in domestic information and electronic enterprises. The developed questionnaire of this study is a method to quantify the organizational innovation. These instrument targets two areas OI and TI evaluation model-to assess innovativeness in an organization.
\end{abstract}

Keywords: Innovation, organizational Innovation, organizational innovativeness inventory, Linear Structural Relation (LISREL), questionnaire

\section{Introduction}

Nonaka (1991) examined the secrets of success of the brand names including Honda, Canon and Panasonic, reporting that the key lied in innovating knowledge management methods, so he called these businesses the knowledge-creating companies, a term similar to the intelligent enterprise, called by Quinn (1992), emphasizing the importance of building up the core competitiveness with knowledge-based capital. Therefore, in the new competitive environment, the competition types lie in how to shape the pattern of competition and promote accumulation of knowledge, how to make good use of diffusion and recreate the organizational structure. The above means that the main competitive advantages of a future business mainly lies in how to keep continuous innovation of knowledge assets, how to absorb external knowledge assets, combined with their existing knowledge and creativity to introduce new technologies, new products, and new management capacity, namely, Organization Innovation, which this study will probe into. Previous studies have often mentioned the term "innovation", with more focus on technical improvements or breakthrough in the techniques. "Innovation" and "Technical Innovation" are often regarded as the same things. Overall, most studies were focused on technological innovation, while relatively less research was directed to organizational innovation. This has highlighted the drawback that there is a lack of interpretation and analysis on the contents and meanings of "innovation theory". Most past researchers on innovation were concerned with the theory of organizational performance improvement and how to enhance the technical capacity to achieve performance targets, but few proposed new concepts of organizational innovation or the related factors in order to enhance organizational performance. This study incorporated management capability and learning organization into their study on the measurement scale of technology capability, so their study focus has been expanded to innovative capability. They defined "innovative capability" as "the overall capacity ability of an organization demonstrated in the performance of individuals, groups, output and structural factors in the process of knowledge innovation". This study further adopted multiple indicators of innovation and defined it as "the breadth and depth of innovation generated by the internally-created or externally-purchased products or management methods of technological innovation.

The breadth of innovation covers the components of "equipment, system, policy, plan, process, product, service and so on". The depth of innovation includes "the influence of every innovation on the organization, the impact, the long-term potential profitability." We can see from above that the components of organizational innovation are complex, and this study aims to foster innovation for the urgent need of information and electronic enterprises in cultivating its innovative capability, to detect the in-depth meanings, its factors and its components of organizational innovation, and to develop a measurement instrument of organizational innovation, in order to construct a more complete theoretical basis for 
organizational innovation. According Rubera and Kirca (2012)view point: In recent years, an increasing body of research has examined how firms' innovative assets and actions (e.g., research \& development investments, patents, new product introductions) contribute to firm performance (e.g., Sorescu \& Spanjol, 2008; Srinivasan et al., 2009; Tellis, Prabhu \& Chandy, 2009).Given this background, this study conducted inventory research on organizational innovation, Process Innovation and Work environment for creativity.

\section{Construction process of organizational innovativeness inventory}

The Preliminary Plan for the Scale Development: The purpose of this study was to develop a scale on the organizational innovation for the high-tech enterprises. After careful tests and revisions based on rigorous research methods, "Organizational innovation Scale on High-tech enterprises" was constructed. This scale integrates "process theory' and "organizational innovation capability" theory, and "innovation capability" was defined from the multiple focuses. In addition to considering the definitions of technical innovation, it also incorporates the definitions of management, echoing the views of many past research findings (Daft, 1978; Damanpour, 1987,1991; Ettlie, et al., 1984; Russell, 1995; Robbins, 1996). Initial assessment framework reference literature included research findings of various scholars on organizational innovation and opinions, and related organizational innovation management empirical research literature, including Daft (1978), Amabile (1988), Damanpour(1987, 1991, 1996), Wolfe (1994), Higgins (1995), Yamin, Gunasekaran \& Mavondo (1999). Furthermore, the data were also compiled from the reference and interviews of experts, scholars and corporate executives.

According to the initial induction of this study, the two major dimensions of organizational innovation detected were Technical Innovation and Administrative Innovation, supporting previous finings of Dual-Core Model (Evan \& Black, 1967 ; Daft, 1978 ; Damanpour, 1991). As to the system dimension of Technical Innovation, it was composed of two dimensions: Product Innovation and Process Innovation. It was developed based on product view, literature review, expert consultation and AHP, which serve as the main component, secondary dimension and index respectively. This initial construction of the measurement model of organizational innovation integrated the findings of a great number of previous literature and findings and the opinions of experts and scholars, so it can be us ed to support or cross examine the empirical findings of these past findings. To construct the scale, firstly, we reviewed the literature and implemented the method of focus group. Second, we designed the scale and sent it to some experts for content validity assessment. Next, we revised the scale questions and test it on samples. Then, based on the effective samples, we did the exploratory factor analysis, and conducted the construct validity analysis. After that, we removed the questions of low interpretability and extracted the common factors for the component names. Finally, we revised the scale and examined its reliability and validity.

Inventory Development: This study has adopted the multiple views in investigating organizational innovation. It has integrated the portfolio theory and the two research approaches of organizational innovation and multiple focuses into the analysis of organizational innovation; hence, the new model has covered both the depth and breadth of organization innovation with a strong theoretical base. Meanwhile, it includes the three major organizational innovation perspectives concluded by Slappendel (1996): individuals, organizations and process interaction. The following will be a summary to the development process of the organizational innovation scale. Assessment of the scale dimensions and proposed questions was to compile and review a lot of related literature then through focus groups. The theoretical basis and referred literature were already discussed in the section of Initial assessment framework and components. This study initially developed seven measurement components: product innovation, process innovation, innovative work environment, marketing innovation, organizational characteristics of innovation, organizational system innovation, and strategy innovation. There is a total of 146 question items. As mentioned above, nineteen experts and scholars were invited to conduct the assessment of content validity and relevance of the initial scale. These experts and scholars assessed the relevance of each question and the component it belongs to. If any item was not appropriate or irrelevant, these experts gave some suggestions on how to revise it. Besides, they also gave the revision suggestions on wording and on the addition or deletion of some question items. This step was to enhance the content validity of the scale.

After getting the comprehensive advice from experts and repeated discussion with my advisor, the formal scale was completed. After substantial amendments, the formal scale has more exact wordings and gets more localized but still keeps the spirit of the original design and diction, in an aim to make the scale easy for domestic employees to fill out and ensures high content validity at the same time. The formal scale has seven components with 146 questions. The sampled employees included the 392 electrical companies which are listed or OTC stocks, which was derived from Taiwan Stock Exchange Commission. In order to raise the response rate, a total of 392 questionnaires were issued to the 392 companies. At the first stage, 98 valid copies (25\% effective response rate) were returned. At the second stage, a total of 290 copies of the questionnaire were issued to the unanswered 290 companies. 30 copies were returned $(10.34 \%$ effective response rate). To sum up, 128 effective copies of the questionnaire were collected and the response rate was $32.65 \%$. Among the 128 effective samples, 30 copies were from the semiconductor companies, 38 copies from the computers and peripherals, 34 from the Communications, and 26 copies from Optoelectronics industry. The study included exploratory factor analysis method of screening subjects. By principal component analysis, items with low interpretability were deleted. The raw data by 
factor analysis, the raw data retained the items of commonality or validity greater than 0.6 and factor loading greater than 0.5 or more to conduct further factor analysis. After re-factor analysis, those questions which showed a commonality greater than 0.6 and the factor loading greater than 0.5 or more were retained. After the principal components analysis, select the common factors of characteristic value (eigenvalue) greater than 1.0 or more, and the greatest variation method (varimax solution) of co-factor orthogonal axis processing, the shaft of each subject for each variable factor loading size difference greater than 0.3 or more. Only the factors with reference to the composition of the meaning of the factors and load factors were renamed, respectively, to facilitate the common factor the identification and naming. Analysis of the results is shown in Table 1 . The organizational innovation scale was determined by exploratory factor analysis of dimensions and assessment items, and there are a total of seven components, 58 questions.

In this study, the internal consistency analysis was conducted on the responded questionnaires. Through internal consistency coefficient Cronbach's calculate coefficients and item-to-total correlation coefficients, the internal consistency of each dimension was analyzed, which was aimed to confirm the consistency and homogeneity of the internal structure of the scale. The assessment of Cronbach's coefficient of the scale dimensions are listed in Table 1, which shows the respective Cronbach's coefficients of the seven subdimensions are greater than 0.7, greater than the number proposed by Nunnally (1978) proposed 0.7, and item-to-total correlation coefficients ranged between 0.5429 and 0.8678 , and most of the coefficient are larger than 0.7. We can see from the above that the scale has a very high level of internal consistency, indicating the scale of the assessment dimensions with a high degree of internal consistency.

Table 1: Factor analysis and summary of reliability analysis of organizational innovation inventory

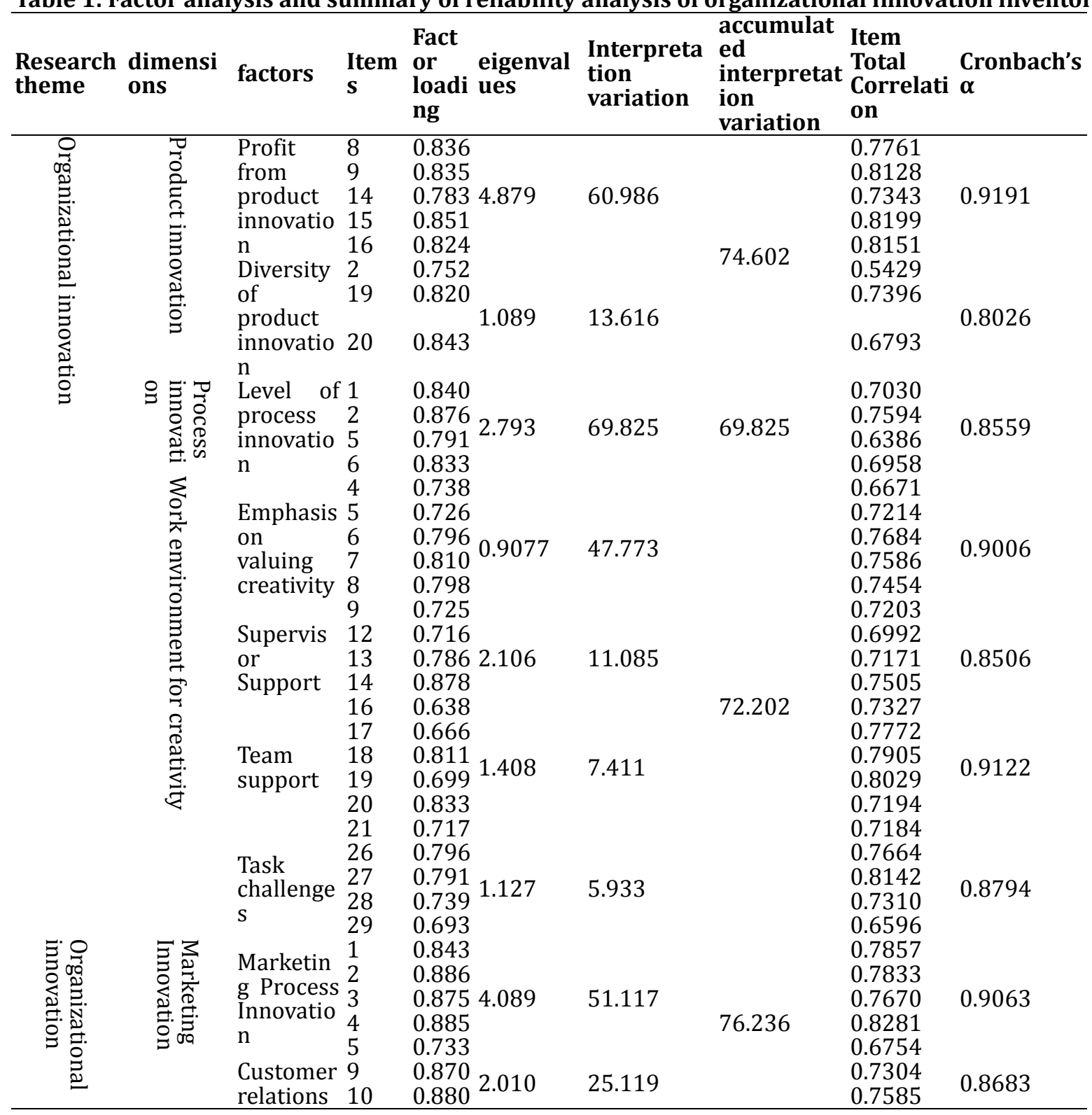




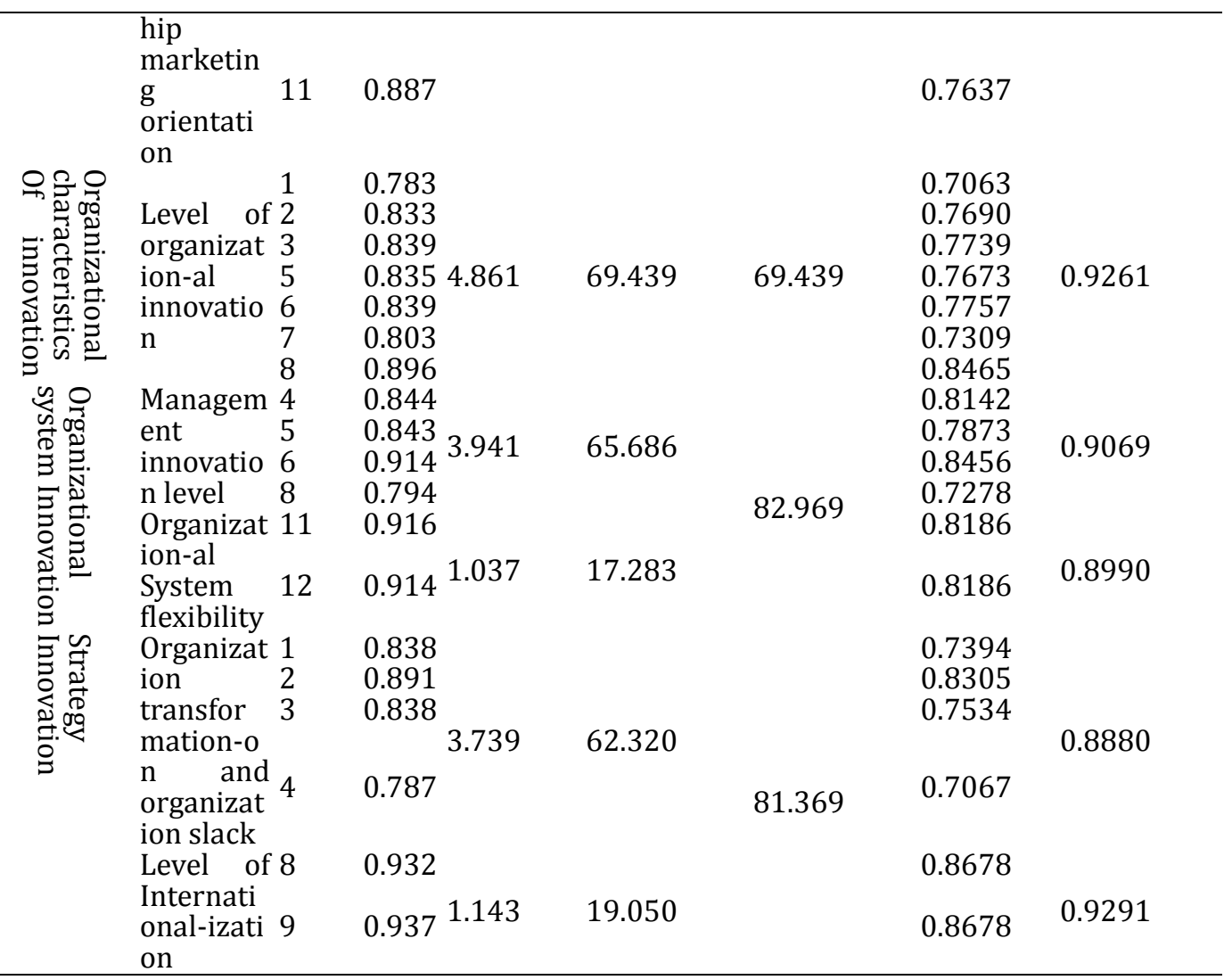

Content Validity: The scale was based on extensive literature, to develop the initial scale of dimensions and items, and then after nineteen organizational innovation management experts to provide evaluation and revisions; modified scale questions composed the formal scale, a large number of questionnaires were issued after the completion of the formal scale. The exploratory factor analysis was conducted to screen the questions of high interpretability. The scale was developed through a rigid process; therefore, the instrument has quite a high content validity.

Concurrent Validity: This scale was referred to the Organizational Innovation Inventory" constructed by Daft (1978) and Damanpour (1987), which collected over 100 employees to re-surveying, to test concurrent validity. Besides multi-factor test scores use the canonical correlation analysis (canonical correlation analysis) to the validity of the test is more appropriate. According to the suggestions above, the items of this scale serve as the components of the predictors (X variables), Daft (1978)"organizational innovation scale" serve as the criterion variables (Y variables) for canonical correlation analysis to identify the scale factor that is typical of a typical weighted correlation coefficient, the maximum $\rho x y$, out of several typical factors typically observed variables and factors related to the components of the scale through the typical factors that can explain the criterion out of scale variation of the percentage of each component That is, the concurrent validity of the scale factor; and to overlap index indicated that the two scales overlap the extent, as the two scale similarity of the measured traits.

Concurrent validity of the scale test of Amabile's (1988) "scale of organizational innovation" as the criterion, was classified into two components of "management innovation" and "technological innovation. It was re- been issued the previously sampled of 100 employees and re-applied test for canonical correlation analysis. The construction of organizational innovation scale consists of seven components, namely: "product innovation", "process innovation", "creativity work environment", "marketing innovation", "organizational characteristics of innovation," "organizational innovation" "policy innovation", the seven components as predictors, as criterion variables are "management innovation" and "technological innovation" two components. Using canonical correlation analysis, linear combination of the two canonical correlation coefficients, coefficients of a typical load and overlap as shown in Table 2 . Canonical correlation analysis shows that the test can be obtained through a significant canonical correlation coefficient square $\rho 1=0.756, \rho 2=0.288$, Wilk's $\Lambda$ values were $0.17387,0.71218, \mathrm{~F}$ values were $23.76945, .08274, \mathrm{P}<0.001$ of significant level. This study adopted canonical correlation analysis test of concurrent validity. The cumulative percentage of variance extracted value of the seven components of this organizational innovation scale reached $69.911 \%$, indicating the scale of the seven variables can explain the typical organizational innovation. The two typical variable scale of $69.911 \%$ variance is the same scale validity coefficients. The number of overlap, and the scale of the seven components of variables through a typical scale of organizational innovation can explain the total variance of all variables of $45.873 \%$. The overlap index indicated that two scales overlap in part of the variation. 
The data obtained from the above show that the developed scale has some similarities with the scale developed by Daft (1978) and Damanpour (1987) in measuring the characteristics of organizational innovation. Therefore, the concurrent validity this study established has a high degree of credibility.

Table 2: Summary of canonical correlation

\begin{tabular}{|c|c|c|c|c|c|}
\hline \multirow{2}{*}{$\begin{array}{l}\text { X variables } \\
\text { Product innovation }\end{array}$} & \multicolumn{2}{|c|}{ Typical factors } & \multirow{2}{*}{$\begin{array}{l}\text { Y variables } \\
\text { Management innovation }\end{array}$} & \multicolumn{2}{|c|}{ Typical factors } \\
\hline & $\begin{array}{l}\chi_{1} \\
0.819\end{array}$ & $\begin{array}{l}\chi_{2} \\
0.25\end{array}$ & & $\eta_{1}$ & $\eta_{2}$ \\
\hline Production innovation & 0.718 & 0.558 & Technical innovation & 0.936 & 0.352 \\
\hline Innovation environment & 0.786 & 0.015 & & & \\
\hline Marketing Innovation & 0.511 & -0.214 & & & \\
\hline $\begin{array}{l}\text { Organization } \\
\text { innovation }\end{array}$ & 0.844 & -0.159 & & & \\
\hline $\begin{array}{l}\text { Organization } \\
\text { innovation }\end{array}$ & 0.872 & -0.445 & & & \\
\hline Strategy innovation & 0.843 & 0.045 & & & \\
\hline Sampling variance $(\%)$ & 60.69 & 9.221 & Sampling variance $(\%)$ & 82.918 & 17.082 \\
\hline Redundancy（\% ) & 62.674 & 4.917 & Redundancy (\% ) & 45.873 & 2.654 \\
\hline & & & & 0.756 & 0.288 \\
\hline & & & $\rho($ canonical correlation $)$ & 0.869 & 0.536 \\
\hline
\end{tabular}

Table 3: Fitness evaluation

\begin{tabular}{ll}
\hline Evaluation items & The results of evaluation \\
\hline The basic standards of adaptation & Yes \\
Is the Error variance not negative? & Yes, they have reached a significant level of \\
Has the error variance reached a significant level? & 0.01.
\end{tabular}

Are the related parameters not too close to the absolute Yes, the absolute value of maximum value? correlation is 0.973 .

Is the factor loading between 0.5 and 0.95 ? Yes, the factor loadings fall between 0.759 and 0.927 .

Is the standard error not great?

Overall model fit criteria (external quality)

Has $\chi^{2}$ not reached a significant level?

No. It has reached the significant level of .000 .

Is the goodness of the fit index (GFI) greater than 0.9 ?

Yes, GFI $=0.975$

Is the adjusted goodness of fit index (AGFI) greater than 0.9 ?

No, AGFI $=0.928$

Is the root mean square residual index (RMR) lower Yes, RMR=0.033 than 0.05 ?

Is the slope of Q-plot of standardized residuals It is a straight line slope of about 45 distribution lines greater than 45 degrees? degrees.

Is the $\chi 2$ value ratio lower than 3 ?

Is the NFI index greater than 0.9 ?

Is the IFI index greater than 0.9 ?

Is the RMSEA index lower than 0.5 ?

No, the ratio is 10.76 .

Yes, NFI $=0.908$

Yes, IFI=0.951

Yes, RMSEA $=0.149$

Is the PNFI index greater than 0.9 ?

No, PNFI $=0.515$

\section{The internal quality of model}

Is the reliability of individual items greater than 0.5 ? Yes

Is the component reliability of the latent variables Yes

greater than 0.6 ?

Have the estimated parameters reached a significant Yes, they all have reached the significant level?

Is the absolute value of standardized residuals lower Ye

than 1.96 ?

Are the modifications indexes lower than 3.84 ? level of 0.01 .

No

Construct Validity: The examination of validation of the scale construction validity adopts LISREL confirmatory factor analysis(CFA). The model contains only the $\mathrm{X}$ variables and potential. There is no relationship between the latent variables. The items were the only factor $(\delta)$. There is no correlation between them. After model validation in the preceding paragraph, if there is a high correlation between the common factors, a further second-order confirmatory factor analysis sub-model validation was 
conducted to extract the common factors of higher order. Sub-model contains only Y variables within potential variables $\eta$ (first-order common factor) and $\xi$ (second-order common factor). The second-order common factor $(\xi)$ has no direct effect on the observed variables. The first stage of the co-factor $(\eta)$ is not directly related to the first-order. The correlation between the common factors has to be explained through the second stage. LISREL model in terms of overall fit to the $\Delta 1, \Delta 2$ and TLI three indices, the theoretical model to $\chi^{2}$ values, degrees of freedom and the baseline model $\chi 2$, degrees of freedom calculated from the comparison. Therefore, first, in the design basis line model, the model assumes no correlation between the variables will be the worst model. From the above three theoretical models of the value index reflects the incremental fitness. Baseline model output yields the results: $\chi 2=220.878(P=$ $0.000)$ and freedom $(\mathrm{DFb})=58$.

Table 4: The discriminant validity analysis table of organizational innovation

\begin{tabular}{|c|c|c|c|}
\hline Model & $\chi^{2}$ & d.f. & $\Delta \chi 2$ \\
\hline non-restricted measurement model & 220.878 & 58 & ---- \\
\hline $\begin{array}{l}\text { Product innovation and process innovation } \\
\text { Correlation coefficient }=1\end{array}$ & 345.676 & 58 & $186.202^{* * *}$ \\
\hline $\begin{array}{lll}\text { Product } & \text { innovation and } & \text { innovation } \\
\text { environment } & \text { Correlation coefficient }=1 & \end{array}$ & 388.924 & 58 & $168.046^{* * *}$ \\
\hline $\begin{array}{l}\text { Product innovation and marketing innovation } \\
\text { Correlation coefficient }=1\end{array}$ & 318.789 & 58 & $97.911^{* * *}$ \\
\hline $\begin{array}{l}\text { Product innovation and organization quality } \\
\text { innovation Correlation coefficient }=1\end{array}$ & 392.667 & 58 & $171.789 * * *$ \\
\hline $\begin{array}{lcc}\text { Product } & \text { Innovation } \quad \text { and } & \text { organizational } \\
\text { Innovation } & \text { Correlation coefficient }=1 & \end{array}$ & 366.888 & 58 & $146.01^{* * *}$ \\
\hline $\begin{array}{l}\text { Product } \quad \text { innovation } \quad \text { and } \\
\text { innovation Correlation coefficient }=1\end{array}$ & 378.928 & 58 & $158.05^{* * *}$ \\
\hline $\begin{array}{l}\text { Process innovation and innovation environment } \\
\text { Correlation coefficient }=1\end{array}$ & 398.222 & 58 & $177.344^{* * *}$ \\
\hline $\begin{array}{l}\text { Process innovation and marketing innovation } \\
\text { Correlation coefficient }=1\end{array}$ & 322.653 & 58 & $102.105^{* * *}$ \\
\hline $\begin{array}{l}\text { Process innovation and organization quality } \\
\text { innovation Correlation coefficient }=1\end{array}$ & 336.983 & 58 & $116.105^{* * *}$ \\
\hline $\begin{array}{l}\text { Process Innovation and } \quad \text { organizational } \\
\text { Innovation Correlation coefficient }=1\end{array}$ & 348.976 & 58 & $128.098^{* * *}$ \\
\hline Correlation coefficient $=1$ & 355.668 & 58 & $134.79 * * *$ \\
\hline $\begin{array}{l}\text { Innovation environment and marketing innovation } \\
\text { Correlation coefficient }=1\end{array}$ & 348.913 & 58 & $128.035^{* * *}$ \\
\hline $\begin{array}{l}\text { Innovation environment and organization quality } \\
\text { innovation Correlation coefficient }=1\end{array}$ & 375.444 & 58 & $154.566^{* * *}$ \\
\hline $\begin{array}{l}\text { Innovation environment and organizational } \\
\text { innovation Correlation coefficient }=1\end{array}$ & 374.456 & 58 & $153.578^{* * *}$ \\
\hline $\begin{array}{l}\text { Innovation environment } \quad \text { and } \\
\text { innovation Correlation coefficient }=1\end{array}$ & 388.666 & 58 & $167.788^{* * *}$ \\
\hline $\begin{array}{l}\text { Marketing innovation and organization quality } \\
\text { innovation Correlation coefficient }=1\end{array}$ & 347.778 & 58 & $126.9^{* * *}$ \\
\hline $\begin{array}{l}\text { Marketing innovation and } \\
\text { innovation Correlation coefficient }=1\end{array}$ & 369.888 & 58 & $149.01^{* * *}$ \\
\hline $\begin{array}{l}\text { Marketing innovation and strategy innovation } \\
\text { Correlation coefficient = } 1\end{array}$ & 322.222 & 58 & $101.344^{* * *}$ \\
\hline $\begin{array}{l}\text { Organization quality innovation and organizational } \\
\text { innovation Correlation coefficient }=1\end{array}$ & 366.777 & 58 & $145.899 * * *$ \\
\hline $\begin{array}{l}\text { Organization quality innovation and strategy } \\
\text { innovation Correlation coefficient }=1\end{array}$ & 355.444 & 58 & $134.566^{* * *}$ \\
\hline $\begin{array}{l}\text { Organizational innovation and strategy innovation } \\
\text { Correlation coefficient }=1\end{array}$ & 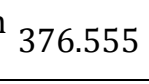 & 58 & $155.677^{* * *}$ \\
\hline
\end{tabular}

The scale and confirmatory factor analysis is estimated by the estimation results for model goodness of fit of the evaluation by using maximum likelihood method (maximum likelihood method).The purpose of fitness evaluation is to evaluate whether it can explain the actual observed data from all aspects of theoretical models. Basic standards in terms of adaptation, the overall model fitness within the standard or model quality, and the vast majority of the projects have achieved the desired standards. From this, we 
can see that the instrument had good convergent validity. The relevant information is shown in Table 3 . This research is based on Anderson and Gerbing (1988) recommendations for discriminate validity of the test. It includes two dimensions: respectively, the two correlation coefficients is limited to 1 , then this limit is not limited to the original model and measurement model card square difference and reliability tests. If the limit model chi-square value than the original measurement model not limited to the chi-square value is large and of significant level, it means that between these two dimensions has discriminate validity. The discriminate validity of the components of this study shows that the pair wise correlation coefficient of dimensions is limited to 1 , set the time limit than those of model chi-square value of the model is not limited to large chi-square value, and reached a significant difference level, so we can see the scale of the dimensions of organizational innovation has discriminate validity between the validity of the data as shown in Table 4 above:

\section{Conclusion and recommendation}

As the present study is orientated toward the measurement of the two major dimensions within an enterprise(i.e. TI and AI), future studies can perhaps add other concepts like industrial innovation, social innovation and national innovation etc. By investigating their interactions with or effects on OI, the context and dimensions of the study model can be supplemented and extended. This will result in a more refined and rigorous measurement model. Although the construction of the present study model was verified and analyzed by incorporating some local information and electronic enterprises during the study, the effectiveness and reliability of the results still need to be confirmed by large sample of enterprises into the study. An OI evaluation model for high-tech enterprises in Taiwan has been established using a rigorous method that involved continuous challenges and modifications. The method combined the orientations of process theory and organizational innovativeness. The study employed multiple viewpoints to define OI, and in agreement with many contemporary researchers view, attempted to incorporate AI, as well as TI into the definition of OI. Since the present model has incorporated the views and opinions from numerous experts and literature, it displayed general agreement with past studies. The major theoretical contribution of the present study is its supplemental purpose to existing OI theory. The dimensions and indicators used to evaluate the OI of information and electronic enterprises being developed not only explained the context of OI, but also formed a platform for studying OI measuring model and applications. In practical terms, results from the present study should be useful guidelines and reference for corporations to improve organization innovativeness.

In spite of various measures being used in the present study to make the model more comprehensive, there still remain a number of unresolved difficulties unresolved. The following recommendations are made for later studies to facilitate further improvements in the model : This include using completely different line of thinking through consulting experts from different industries to take into account the nature and difference between dissimilar industries, Also, we need to investigate the design of measurement indicators for individual industrial sectors. The above results showed that for an enterprise, the importance of TI appeared to be greater than AI. It must however be stressed that the activities of AI and TI can mutually promote and have synergistic effects in enhancing the adaptability of an enterprise to environmental changes. Therefore, the present measurement model should be helpful for an enterprise in understanding its current OI status, providing strategic recommendations, and acting as a guideline for improving OI activities to better its competitiveness of organizations. Innovativeness need to be examined as part of the strategy to make the organization competitive. New innovativeness of organizations is the most important factor that will drive the future of the organization (Adisu, 2014). The innovation process should not focus on the management only; rather this phenomenon should be organization-wide (Brubaker, 2012).

\section{References}

Adisu, K. (2014). Chinese Economic Development and Leadership Strategy: The Challenges of Creating Competitive Advantage. Journal of Economics and Behavioral Studies, 6(2), 163-168.

Amabile, T. M. (1988). A Model of Creativity and Innovation in Organization. Edited by Behavior, 10, $123-167$.

Anderson, J. C. \& Gerbing, C. W. (1988). Structural Equation Modeling in Practice: A Review and Recommended Two-Step Approach. Psychological Bulletin, 103(3), 411-423.

Becker, S. W. \& Whisler, T. L. (1967). The innovative organization: A selective view of current theory and research. Journal of Business, 4, 462-469.

Brubaker, T. A. (2012). Measuring Political Perceptions in Organizations: Assessing Reliability and Validity of POPS across Cultures. Journal of Economics \& Behavioral Studies, 4(10), 603-611.

Daft, R. L. (1978). A Dual-core Model of Organization Innovation. Academy of Management Journal, 21, 193-210.

Damanpour, F. (1987). The Adoption of Technological, Administrative, and Ancillary Innovations: Impact of Organizational Factors. Journal of Management, 13, 675-688.

Damanpour, F. (1991). Organizational Innovation: A Meta Analysis of Effects of Determinants and Moderators. Academy of Management Journal, 34(3), 555-590. 
Damanpour, F. (1996). Organizational Complexity and Innovation: Developing and Testing Multiple Contingency Models. Management Science, 42, 693-716.

Ettlie, J. E., Bridges, W. P. \& O'Keefe, R. D. (1984). Organization Strategy and Structural Differences for Radical versus Incremental Innovation. Management Journal, 30, 682-695.

Evan, W. M. \& Black, G. (1967). Innovation in Business Organization: Some Factors Associated with Success or Failure. Journal of Business, 40, 519-530.

Higgins, J. M. (1995). Innovation: the core competence. Planning Review, 23, 32-36.

Hurley, R. F., Hult, G. \& Tomas M.(1998). Innovation, Market Orientation, and Organizational Learning : An Integration and Empirical Examination. Journal of Marketing, 62(3), 42-54.

Knight, K. E. (1967). A Descriptive Model of the Intra-firm Innovation Process. Journal of Business, 40, 478-496.

Nonaka, I. (1991). The Knowledge-creating Company. Harvard Business Review, 96-104.

Nunnally, J. C. (1978). Psychometric Theory, 2nd edition, New York: McGraw-Hill.

Quinn, J. B. (1992). The intelligent enterprise a new paradigm. Academy of Management Executive, 6(4), 48-63.

Robbins, S. P. (1996). Organizational behavior: Concepts, controversies and Applications. Englewood Cliffs, N. J. Prentice-Hall.

Rubera, K. \& Kirca, L. (2012). Firm Innovativeness and Its Performance Outcomes: A Meta-Analytic Review and Theoretical Integration. Journal of Marketing, 76, 130-147.

Russell, R. D. (1995). An investigation of some organizational correlates of corporate entrepreneurship: Toward a systems model of organizational innovation. Entrepreneurship, Innovation, and Change, 4(4), 295-314.

Shepard, H. A. (1967). Innovation-resistion and Innovation-producing Organizations. Journal of Business, $4,470-477$

Slappendel, C. (1996). Perspectives on innovation in organizations. Organization Studies, 17(1), 107-129.

Sorescu, A. \& Spanjol, J. (2008). Innovation's Effect on Firm Value and Risk: Insights from Consumer Packaged Goods. Journal of Marketing, 72(5), 114-32.

Srinivasan, S. \& Hanssens, D. M. (2009). Marketing and Firm Value: Metrics, Methods, Findings, and Future Directions. Journal of Marketing Research, 46(6), 293-312.

Tellis, J., Prabhu, C. \& Chandy, R. K. (2009). Radical Innovation Across Nations: The Preeminence of corporate Culture. Journal of Marketing, 73(1), 3-23.

Wolfe, R. A. (1994). Organizational Innovation: Review, Critique and Suggested Research Directions. Journal of Management Studies, 31(3), 405-430.

Yamin, S., Gunasekaran, A. \& Mavondo, F. T. (1999). Innovation index and its implications on organizational performance: A study of Australian manufacturing companies. International Journal of Technology Management, Geneva, 17(5), 495-503. 